\title{
Measurement of Dry and Autogenous Shrinkages and Thermal Strain of Early Age Concrete Pavement
}

\author{
Jaewook Ku', Seunghyun Roh², Hyunsik Hwang, ${ }^{3, *}$
}

1 Korea Expressway Corporation, 77, Hyeoksin 8-ro, Gimcheon-si, Gyeongsangbuk-do, Republic of Korea 39660; imweeping@ex.co.kr

2 Department of Civil and Environmental Engineering, Chung-Ang University, 84 HeukSeok-Dong, DongJakGu, Seoul, Republic of Korea 06974 ; shroh8@naver.com

3 Department of Civil and Environmental Engineering, Chung-Ang University, 84 HeukSeok-Dong, DongJakGu, Seoul, Republic of Korea(06974); cau.hhs@gmail.com

* Correspondence: cau.hhs@gmail.com; Tel.: +82-10-9263-8226 (optional; include country code; if there are multiple corresponding authors, add author initials)

\begin{abstract}
Background: Early-age concrete shrinkage induces stress that impact the cost and service life of concrete pavements. (2)Methods: In this study, strain measurements of field slabs were conducted and a methodology was presented that independently derived autogenous, drying, and thermal shrinkages in the initial stages of concrete placement. Total strain was measured according to five different environmental conditions and shrinkage strain was calculated for each condition. (3)Results: By measuring the strain of the slab and the specimen, the drying shrinkage strain was measured to be approximately $54 \%$ better than that by the conventional nonstressed cylinder method because it was possible to measure the drying shrinkage strain at the surface rather than in the middle part of the slab along its depth direction. When the water-to-cement ratio increased $(35 \rightarrow 40 \%)$, there was a considerable reduction $(317 \mu \varepsilon \rightarrow 82 \mu \varepsilon)$ of autogenous shrinkage strain for the concrete at 28 days of age. Furthermore, calculation of stress-dependent strain allowed the presentation of more intuitive and accurate results. (4)Conclusion: As the measurement of independent shrinkage occurrence is possible, the consequent calculated result of the stress-dependent strain acting on real slabs will facilitate improvement in the construction quality, reduction in the development of defects in the concrete structure, and increase in the service life.
\end{abstract}

Keywords: Pavement; Concrete shrinkage; Concrete behavior.

\section{Introduction}

Concrete is the most extensively used construction material worldwide. Portland cement concrete pavement was first designed in the United States in 1892. Since then, concrete has been applied as a paving material for various infrastructures such as roads, ports, and airports [1]. As the safety and durability of these infrastructures is critical, the cost of repair and service life need to assessed carefully. The service life of concrete is evaluated in terms of physical strength, durability, and serviceability.

The physical strength of concrete varies with age and setting time. During this earlyage period, two main reactions occur: setting process with progressive loss of fluidity, and hardening process with gaining of strength [2]. During the process of hydration, concrete undergoes a transition from a fluid to a hardened structure; however, before the final setting, concrete does not develop a sufficient tensile strength. Hence, usage of concrete before the final setting leads to a high-risk of defect formation. Accordingly, proper construction quality control is necessary [3].

Shrinkage occurs in concrete during the hydration process. For general concrete, in the first phase (within $24 \mathrm{~h}$ after placement), the unhardened concrete begins to harden, and chemical shrinkage occurs during the setting process. The second phase refers to the period $\sim 24 \mathrm{~h}$ after placement, wherein autogenous, drying, and thermal shrinkage occur. The three types of shrinkage yield the same shrinkage outcome in terms of concrete 
materials, but each type of shrinkage is caused by different mechanisms [4-8]. The process adopted from the placement of concrete to its final setting is illustrated in Figure 1.

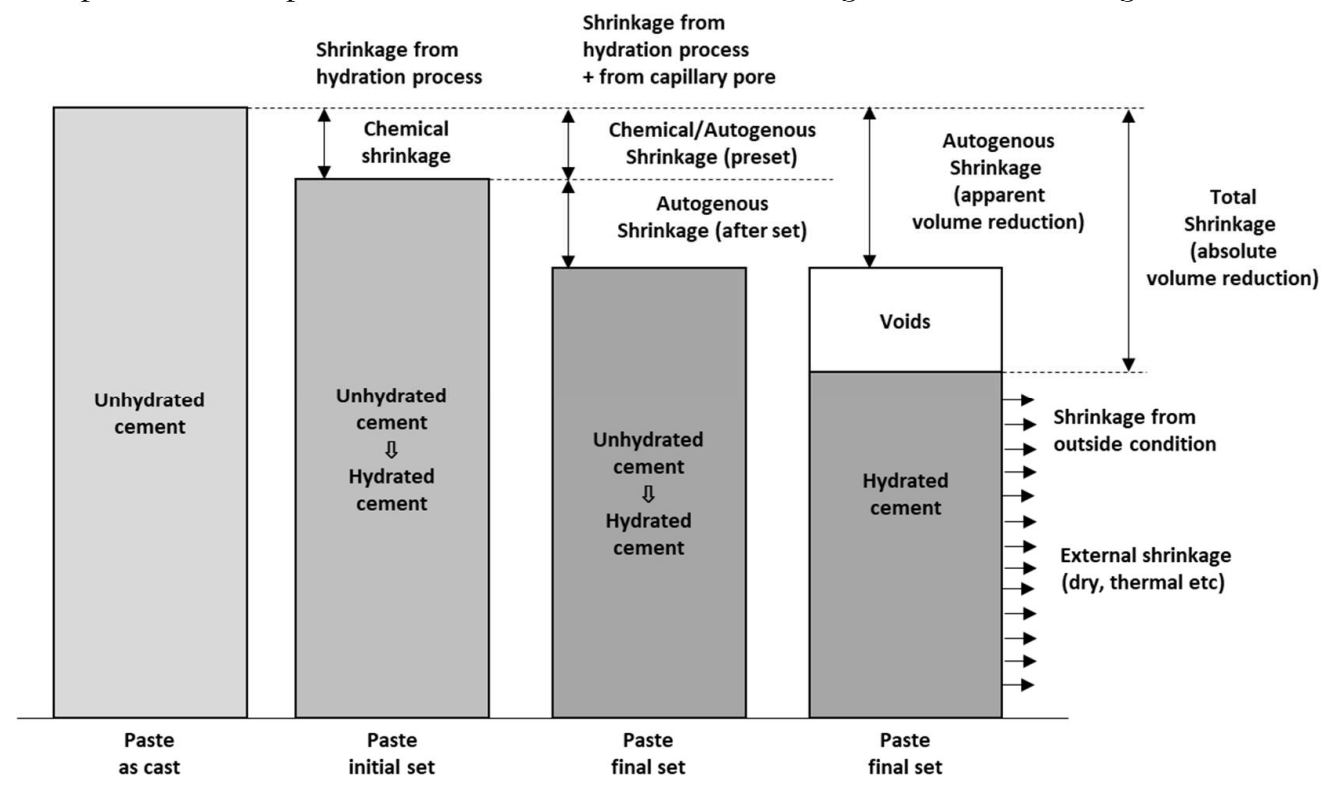

Figure 1. Concrete shrinkage process from its placement to the final setting.

Drying shrinkage is a consequence of loss of moisture from hardened concrete to the environment. Following moisture diffusion from the surface to the outside, shrinkage is caused owing to changes in the capillary pressure, disjoining pressure, and surface tension $[9,10]$. Previous studies have reported that as the distribution of moisture in the cross-section of concrete is not uniform, greater shrinkage is induced on the surface, thus resulting in tensile stress. The shrinkage will progress over a long time until the until the cement's humidity equilibrates with that of the external environment, thus causing serious problems in the durability of the concrete [11]. Drying shrinkage decreases with increasing strength and decreasing water-to-cement ratio (w/c ratio), but is significantly affected by external factors, such as the size of the member and relative humidity [12, 13]. However, the final drying shrinkage increases as the relative humidity decreases, and the size of the member may affect the rate of the progress of the drying shrinkage but does not affect the final amount of drying shrinkage. Drying shrinkage cracks formed on the surface typically propagate to a depth of $2-3 \mathrm{~cm}$ from the surface, which may not cause a significant problem in the initial phase; however, these cracks may develop and become a major cause of durability defects during long-term use [14].

Among the various types of concrete shrinkage at the initial stage of placement, autogenous shrinkage can be defined as the macroscopic volume change that occurs after the initial setting as a result of the elimination of moisture from capillary pores in continuation of cement hydration reactions [15]. The process of autogenous shrinkage can be described as a process of self-desiccation in which unhydrated cement particles during the early stage of hardening gradually eliminate the internal moisture and undergo hydration and contraction [16]. Nowadays, concrete exhibits high strength/durability achieved by lowering the w/c ratio and adding silica-fume. However, published reports have indicated that the change in the internal humidity from hydration increases, and this has a dominant impact on the occurrence of early cracks [17]. These findings indicate that in the case of high-strength (high-performance) concrete, cracks can be formed owing to changes in the volume [18]. Another previous study reported that in the case of autogenous shrinkage, pore humidity drops owing to internal hydration and it is not affected by the depth of the mixture or ambient humidity [19]. 
Conventional methods for measurement of autogenous shrinkage strain or volume change involved placing cement paste in a rubber membrane, immersing it in a water bath, and measuring the shrinkage by the change in the water level [20]. In another method (Figure 2), stress-dependent strain was derived using a nonstressed cylinder (NC) for the in-situ evaluation of initial stress generation for concrete structures [21, 22, 23].
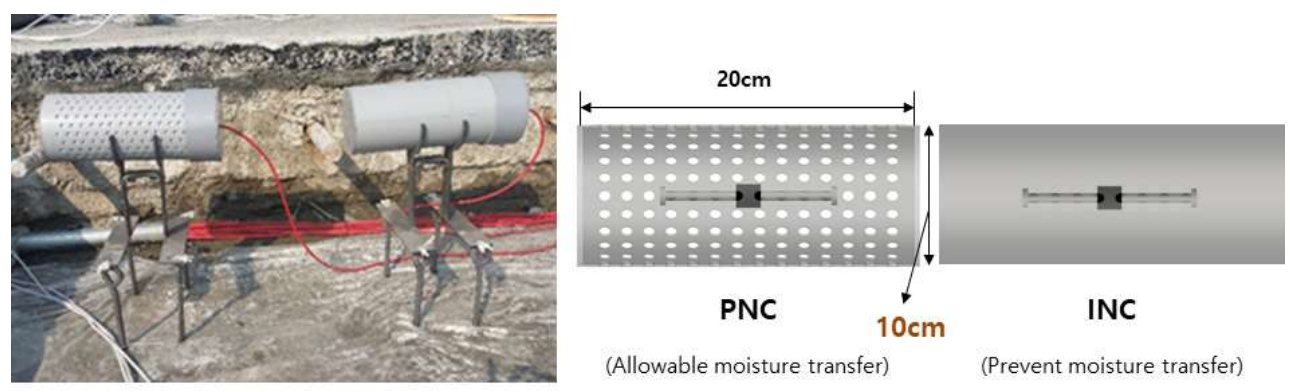

Figure 2. Evaluation method of early-age concrete using nonstressed cylinder in field.

Among these methods, the concept of non-stressed cylinder was used as a reference method for comparison in this study. Total strain can be divided into four types of strain (i.e., elastic, creep, shrinkage, and thermal). The respective types of strain can be expressed according to Equation (1).

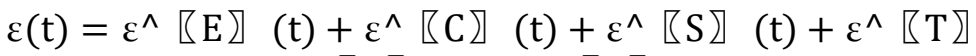

$$
\begin{aligned}
& =\varepsilon^{\wedge}[\sigma] \\
& \text { (t) }+\varepsilon^{\wedge}[0)
\end{aligned}
$$

where $\varepsilon(t)$ is the total strain, $\varepsilon^{\wedge}[E \mathrm{E})(\mathrm{t})$ is the elastic strain, $\varepsilon^{\wedge}[\mathrm{C})(\mathrm{t})$ is the creep strain; $\varepsilon^{\wedge}[\mathrm{S})(\mathrm{t})$ is the shrinkage strain, $\varepsilon^{\wedge}[\mathrm{T} \Omega(\mathrm{t})$ is the thermal strain, $\varepsilon^{\wedge}[\sigma](\mathrm{t})=\varepsilon^{\wedge}[\mathrm{E}\rangle(\mathrm{t})+\varepsilon^{\wedge}\left[\mathrm{C} \Sigma(\mathrm{t})\right.$ is the stress-dependent strain, and $\varepsilon^{\wedge}$ $\left[0 \Omega(\mathrm{t})=\varepsilon^{\wedge} \llbracket \mathrm{S} \Omega(\mathrm{t})+\varepsilon^{\wedge}[\mathrm{T}\rangle(\mathrm{t})\right.$ is the stress-independent strain.

This study presents a methodology to derive independent drying and autogenous shrinkage in the initial stage of concrete placement. Given that the measurement of the independent shrinkage occurrence becomes possible, improvement in the construction quality and reduction in the number of developed defects in the concrete structure, and increase in the service life are expected based on the calculation result of the stress-dependent strain that acts on the actual slabs.

\section{Materials and Methods}

The basic concept used for the measurement of the shrinkage behavior of early-age concrete is presented schematically in Figure 3. First, consider the difference between a cantilever beam, which develops strain (but no stress) due to temperature changes, and a fixed end beam in which both ends are fixed (thus, it has stress but no strain). In the case of a beam specimen, rollers are installed at both ends of the bottom part of the specimen to induce a free beam to implement a cantilever-like behavior. In addition, for the field slab, a fixed end-beam behavior is induced owing to friction at the bottom part of the specimen to evaluate the shrinkage behavior of early-age concrete. 


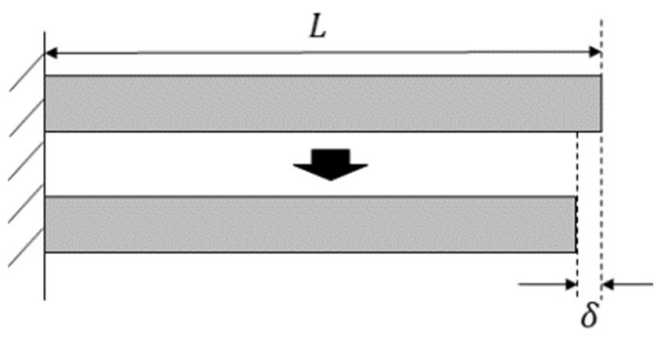

(a) Cantilever beam

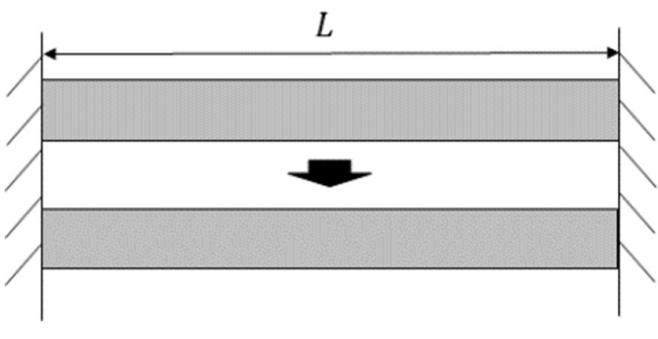

(b) Fixed-end beam

Figure 3. Basic concept adopted for the measurement of shrinkage behavior.

Using the aforementioned concept, the conventional non-stressed cylinder method and the proposed method of fabricating an environment-controlled beam were evaluated and compared. For the proposed methodology, as shown in Figure 4, the entire front surface of two beam specimens were wrapped with aluminum tape; the surface of the other two specimens was exposed to air to fabricate four specimens. A GEOKON's Vibrating Wire Strain Gage (VWSG) sensor was installed at a depth of $3 \mathrm{~cm}$ from the surface layer of the specimen and field slab to evaluate the effect of surface drying.
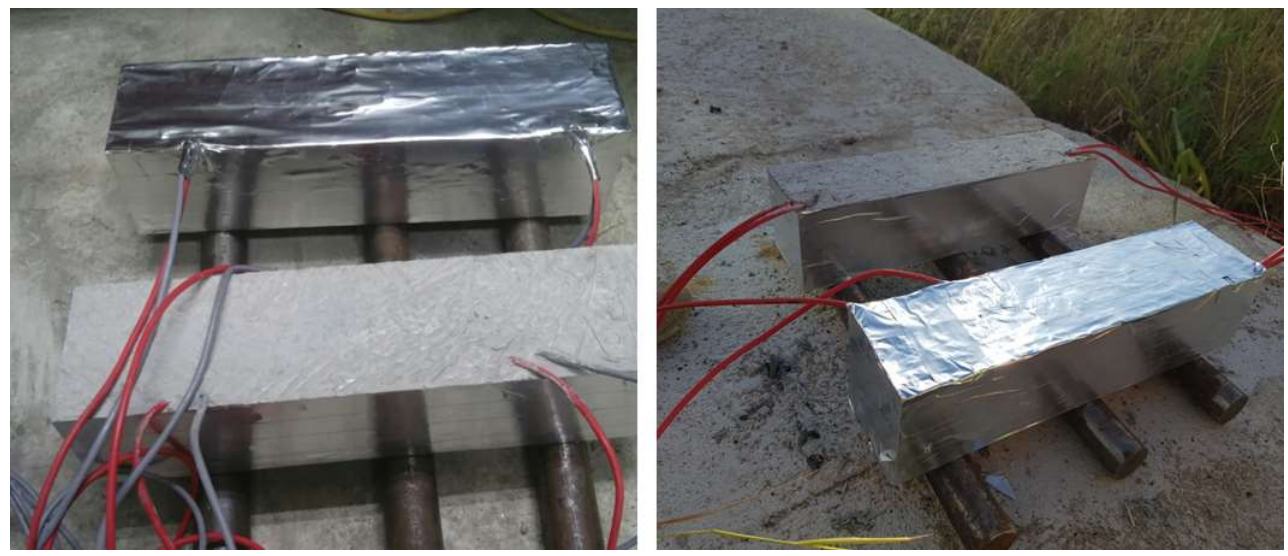

Figure 4. Environment-controlled specimens in (left) chamber and (right) field.

In particular, in an environment where the temperature is kept constant (e.g., in a chamber in which the specimen with its front surface is covered with aluminum tape), there is no influence from the external environment, and shrinkage occurs only due to the early-age hydration. In the case of the experimental design, as shown in Figure 5, the allblocked specimen undergoes shrinkage regardless of the location, whereas the topopened specimen is exposed to the external environment and different levels of shrinkage are measured depending on the depth of the specimen. Based on these differences, each shrinkage may occur during the hydration process of early-age cement concrete. 

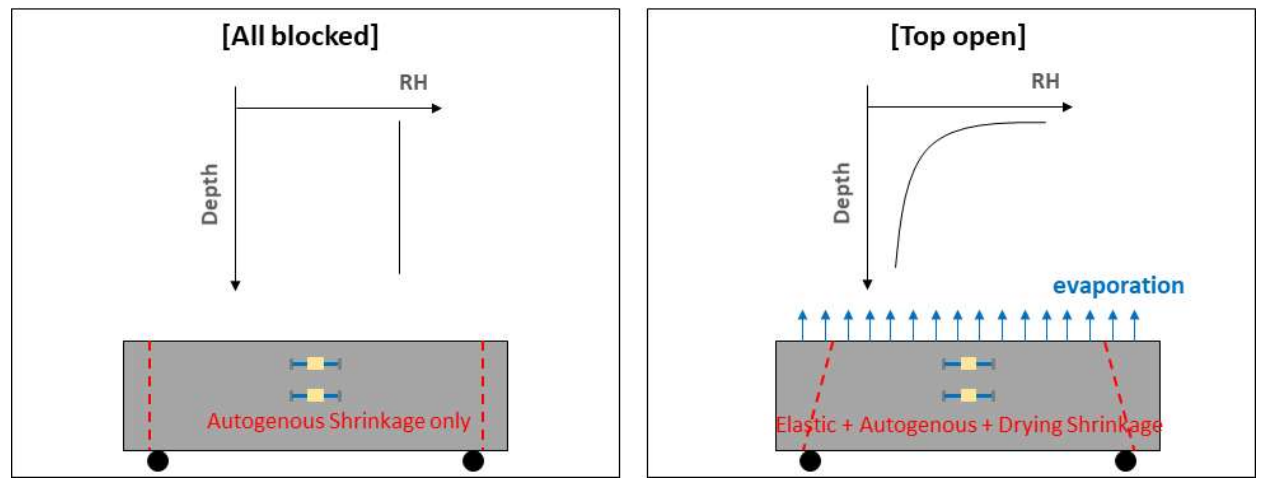

Figure 5. Concept of environment control method for measuring each shrinkage strain.

The top open and all-blocked specimens are located in the field and in the environmental chamber, respectively; hence, the temperature and humidity conditions can be varied as shown in Table 1. $\varepsilon_{-}$『1】 represents a top open specimen in the field, and is subject to all the effects of thermal, drying, and autogenous shrinkage. $\varepsilon_{-}$『2】 represents an all-blocked specimen in the field, which reflects the effect of temperature but blocks humidity to control the change in humidity due to external influences. $\varepsilon_{-}$『3】 represents a top-open specimen in an environmental chamber with temperature and humidity controlled at constant values of $20^{\circ} \mathrm{C}$ and $50 \%$, respectively. Humidity loss through the surface was possible. Thus, only drying and autogenous shrinkage occurred in the specimen. $\varepsilon_{-}$\4】 represents an all-blocked specimen in an environmental chamber in which the temperature and humidity are controlled, and only autogenous shrinkage can occur. Finally, $\varepsilon_{-} \llbracket 5 \rrbracket$ represents the same conditions as $\varepsilon_{-} \llbracket 1 \rrbracket$; however, the sensor is installed in the field slab and not the beam specimen to measure the total strain at the reallife pavement.

Based on the concept of NC(Non-stressed Cylinder) for thermal strain measurement, the impervious NC (INC) specimen embedded in the field was free from external stress and only the strain caused by the effect of temperature occurred in the specimen. Conversely, in the proposed methodology, given that autogenous shrinkage strain occurred in all conditions, from the strain of the all-blocked specimen installed in the field, the strain of the all-blocked specimens in the chamber that measures only the autogenous shrinkage strain can be subtracted to derive pure thermal strain.

To measure drying shrinkage strain according to the NC concept, the value obtained by subtracting the INC strain from the strain of porous NC (PNC) specimen was reported. However, NC specimens can be installed in the middle part of the pavement (along its depth direction). Nevertheless, this introduces a limitation in that the reported shrinkage will not reflect the most critical drying shrinkage on the pavement surface. In the proposed new methodology, only the drying shrinkage strain, which develops on the pavement surface, can be derived by subtracting the strain of the all-blocked specimen $\left(\varepsilon_{-}\right.$ $\llbracket 2 \rrbracket)$ from the top open specimen strain ( $\left.\varepsilon_{-} \llbracket 1 \rrbracket\right)$ in the field.

Stress-dependent strain can be calculated as the difference between the strain $\left(\varepsilon_{-}\right.$ 『1】) of the free-beam specimen and the total strain $\left(\varepsilon_{-} \llbracket 5 \rrbracket\right)$ generated by the real environmental load of the field slab whose lower motion is restricted. 
Table 1. Definition of shrinkage conditions to evaluate concrete's early-age behavior.

\begin{tabular}{|c|c|c|c|c|c|}
\hline & \multicolumn{4}{|c|}{ Beam Specimen } & \multirow{3}{*}{ Field slab } \\
\hline & \multicolumn{2}{|c|}{ Field } & \multicolumn{2}{|c|}{ Chamber } & \\
\hline & Top open & All blocked & Top open & All blocked & \\
\hline Temperature & change & change & Steady & Steady & change \\
\hline Humidity & change & Steady & change & Steady & change \\
\hline Simulation & $\begin{array}{c}\text { (thermal }+ \text { drying }+ \\
\text { autogenous) }\end{array}$ & $\begin{array}{c}\text { (thermal + autoge- } \\
\text { nous) }\end{array}$ & $\begin{array}{c}\text { (drying + autoge- } \\
\text { nous) }\end{array}$ & (autogenous) & $\begin{array}{c}\text { (thermal }+ \text { drying + } \\
\text { autogenous) }\end{array}$ \\
\hline Symbol & $\mathrm{a}\left(\varepsilon_{-} \llbracket 1 \rrbracket\right)$ & $\mathrm{b}\left(\varepsilon_{-} \llbracket 2 \rrbracket\right)$ & $c\left(\varepsilon_{-} \llbracket 3 \rrbracket\right)$ & $\mathrm{d}\left(\varepsilon_{-} \llbracket 4 \rrbracket\right)$ & $\mathrm{e}\left(\varepsilon_{-} \llbracket 5 \rrbracket\right)$ \\
\hline
\end{tabular}

The material used for the investigation of the behavior of the early-age concrete is a mix of joint concrete pavement (JCP) and type 1 cement. Two types of mix designs were selected according to the results of a previous study that reported a significant increase of autogenous shrinkage strain when the w/c ratio was less than $40 \%$ [24], as shown in Table 2 .

Table 2. Cement concrete mix design (W/C: water-to-cement ratio, S/A: sand-to-aggregate ratio).

\begin{tabular}{|c|c|c|c|c|c|c|c|c|}
\hline \multirow{2}{*}{$\begin{array}{c}\text { Maxi- } \\
\text { mum } \\
\text { aggre- } \\
\text { gate } \\
\text { size } \\
(\mathrm{mm})\end{array}$} & \multirow[b]{2}{*}{$\begin{array}{l}\text { Slump } \\
(\mathrm{cm})\end{array}$} & \multirow[b]{2}{*}{$\begin{array}{l}\text { W/C } \\
(\%)\end{array}$} & \multirow[b]{2}{*}{$\begin{array}{l}\text { S/A } \\
(\%)\end{array}$} & \multicolumn{5}{|c|}{ Unit Weight $\left(\mathrm{kg} / \mathrm{m}^{3}\right)$} \\
\hline & & & & Water & Cement & Sand & Aggregate & $\begin{array}{l}\text { Mineral Ad- } \\
\text { mixture }\end{array}$ \\
\hline 25 & 2.5 & 35 & 38 & 150 & 440 & 600 & 1,200 & $2-5$ \\
\hline 25 & $8 \pm 2.5$ & 40 & 46.6 & 121 & 390 & 856 & 902 & 2.34 \\
\hline
\end{tabular}

\section{Results}

\subsection{Test Method Validation}

Concrete shrinks as the heat of hydration decreases after volume expansion from the early-age hydration stage; hence, it is important to define the point at which the stress becomes zero. For the calculation of shrinkage strain, a reference point of zero strain is required, and the temperature of the concrete at this point is referred to as the zero strain temperature (ZST). According to results from previous studies, the reduction factor, which quantifies the relationship between ZST and the peak hydration temperature, ranges from 6 to $8 \%$ on average as a function of various parameters, thus indicating that ZST occurs at 92 to $94 \%$ of the peak hydration temperature of concrete [25, 26]. In this study, $94 \%$ of peak hydration temperature was defined as ZST as shown in Figure 6. 


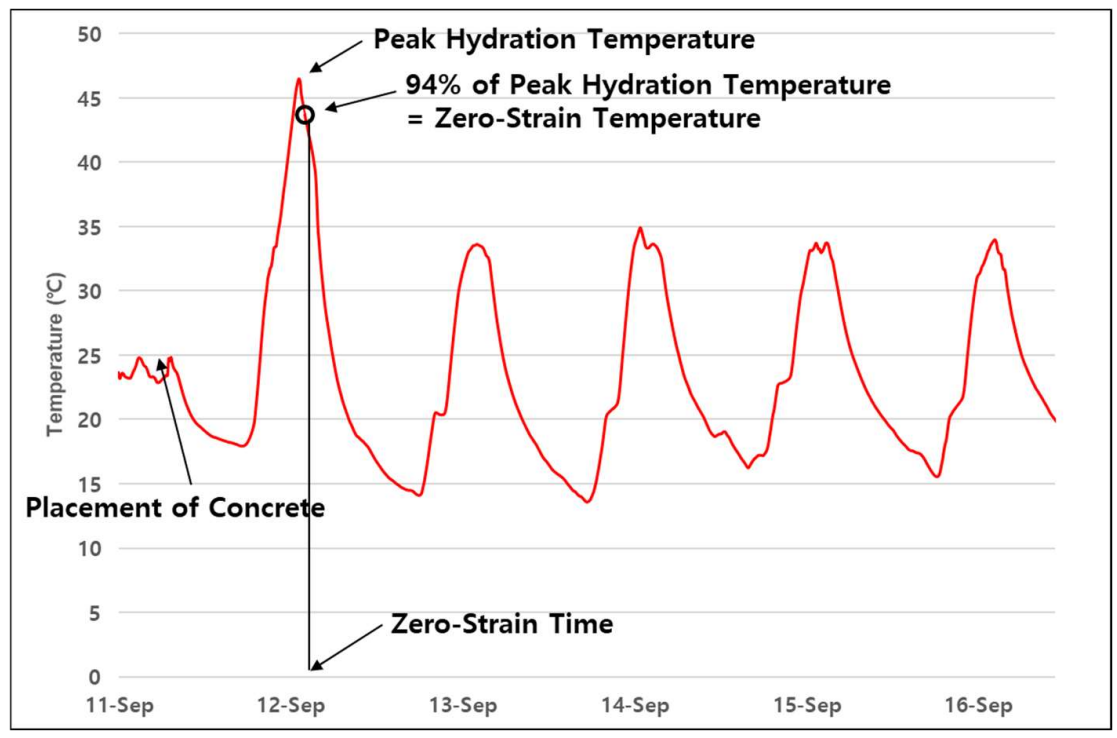

Figure 6. Method adopted to select the zero-strain temperature.

A preliminary test was first conducted to validate the specimen evaluation method at different environmental conditions using the aluminum tape. Two VWSG sensors were embedded for each of the four beam specimens at $3 \mathrm{~cm}$ and $5 \mathrm{~cm}$ from the surface layer. Two specimens were installed in an environment-controlled chamber with temperature and humidity controlled at constant values (temperature: $20^{\circ} \mathrm{C}$, humidity: $50 \%$ ), and the other two specimens were exposed to the environment, and were thus subjected to changes in the temperature and humidity. In the preliminary test, evaluation was performed with a w/c ratio set at $35 \%$.

The results of the preliminary test (shown in Figure 7) indicate that there was a difference in strain in the top open specimens for both the field and chamber specimens. The strain at $3 \mathrm{~cm}$ from the surface layer was approximately 100-150 $\mu \varepsilon$ larger than that at 5 $\mathrm{cm}$. Conversely, when the entire front surface of the specimen was blocked with aluminum tape, the difference between $3 \mathrm{~cm}$ and $5 \mathrm{~cm}$ strain was $20 \mu \varepsilon$ or less, which yielded similar results between the two cases.

The result signifies that with the methodology proposed in this study, the environmental conditions for the early-age behavior analysis of concrete mixture can be controlled and drying and autogenous shrinkages of the mixture can be measured. 


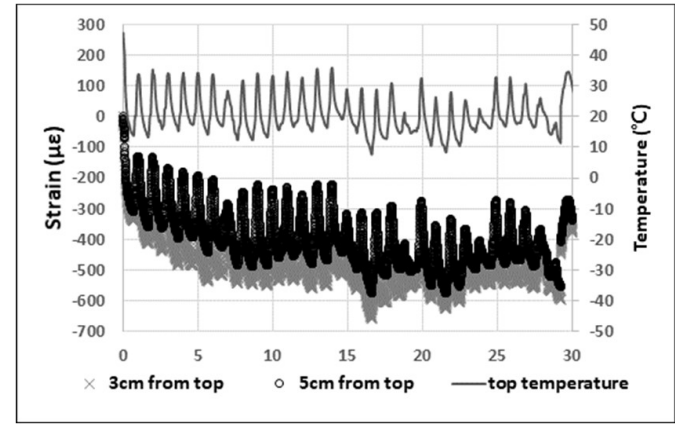

(a) Field Top-Open Specimen

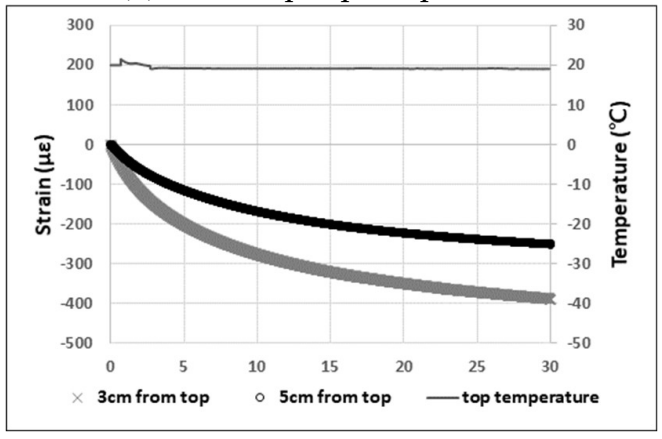

(c) Chamber Top-Open Specimen

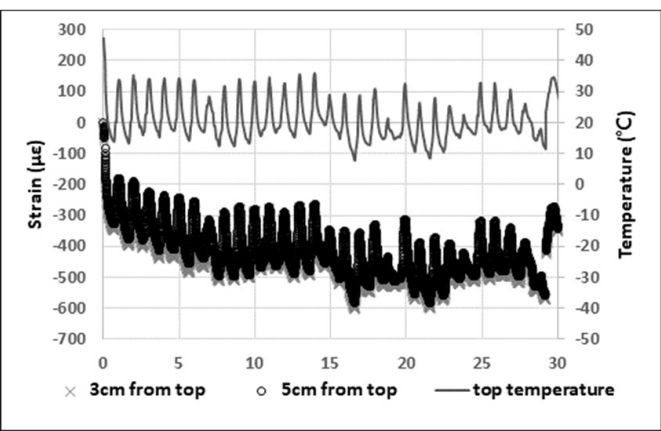

(b) Field All-blocked Specimen

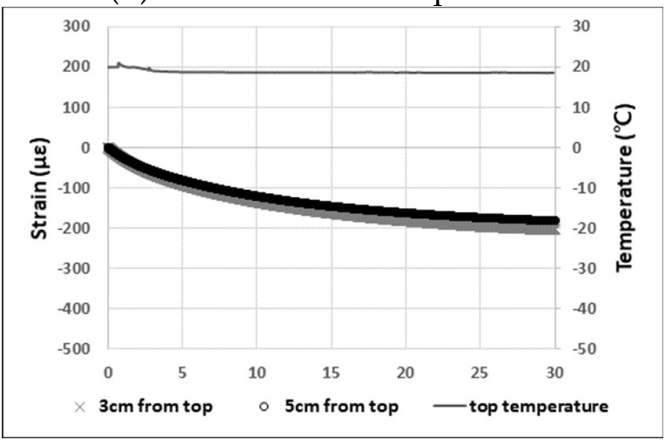

(d) Chamber All-Blocked Specimen

Figure 7. Preliminary test results used to validate environment control in field and chamber conditions.

\subsection{Measurement of Environment-controlled Total Strain}

As shown in Figure 8, the field slab was a square of length $6 \mathrm{~m}$, and a height of 0.42 $\mathrm{m}$; this is classified as a thick cement concrete pavement. As outlined in Table 3, strain sensors were installed at the top, middle, and bottom parts, respectively, to measure the total strain of the field slab. The conventional NC used in previous studies was also installed. Regarding the environment-controlled beam specimen, two specimens were installed in the field and chamber, respectively, and two different conditions of top-open and all-blocked were applied.

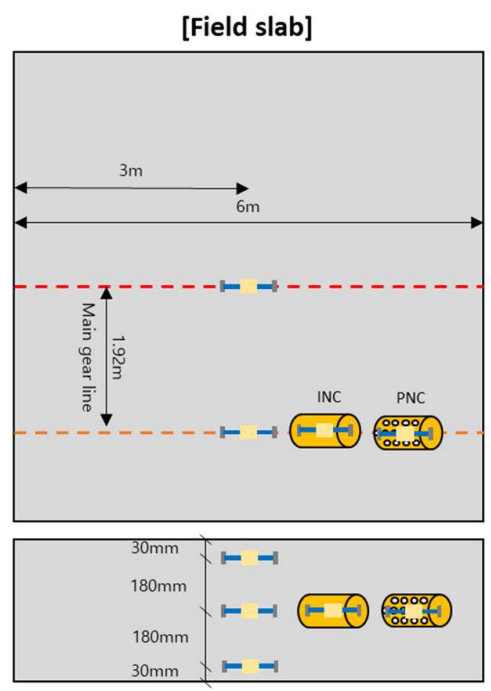

[Field beam]


[Chamber beam]
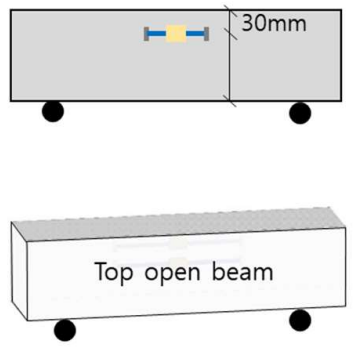

All-blocked beam

Figure 8. Schematic showing field-sensor application. 
Table 3. Application sensors used for evaluation (NC: nonstressed cylinder, INC: impervious, PNC: porous NC).

\begin{tabular}{|c|c|c|c|c|c|c|c|c|}
\hline \multicolumn{3}{|c|}{ Field slab } & \multicolumn{3}{|c|}{ Field beam } & \multicolumn{3}{|c|}{ Chamber beam } \\
\hline \multicolumn{2}{|c|}{ Location } & \multirow{2}{*}{$\begin{array}{c}\text { EA } \\
1\end{array}$} & \multicolumn{2}{|c|}{ Location } & \multirow[t]{2}{*}{ EA } & \multicolumn{2}{|c|}{ Location } & \multirow[t]{2}{*}{ EA } \\
\hline \multirow{3}{*}{ center } & top & & \multirow{3}{*}{ top open } & \multirow{3}{*}{ top } & & \multirow{3}{*}{ top open } & \multirow{3}{*}{ top } & \\
\hline & middle & 1 & & & \multirow[t]{2}{*}{1} & & & 1 \\
\hline & bottom & 1 & & & & & & \\
\hline \multirow{2}{*}{$\mathrm{NC}$} & INC & 1 & \multirow[t]{2}{*}{ all blocked } & \multirow[t]{2}{*}{ top } & \multirow[t]{2}{*}{1} & \multirow[t]{2}{*}{ all blocked } & \multirow[t]{2}{*}{ top } & \multirow[t]{2}{*}{1} \\
\hline & PNC & 1 & & & & & & \\
\hline \multicolumn{2}{|c|}{ Total } & 8 & \multicolumn{2}{|c|}{ Total } & 2 & \multicolumn{2}{|c|}{ Total } & 2 \\
\hline
\end{tabular}

The total strain at different depths of the strain system directly embedded in the field slab shows that shrinkage continues to progress after the peak temperature is reached owing to the hydration of concrete. As expected, the strain at a depth of $3 \mathrm{~cm}$ from the surface of the concrete slab was the largest, and the strain at the bottom was the smallest. Figure 9 shows that in the process of concrete drying, the distribution of moisture and temperature inside the pavement is not uniform. Given that the bottom part is constrained, larger shrinkage is observed on the surface of the concrete.

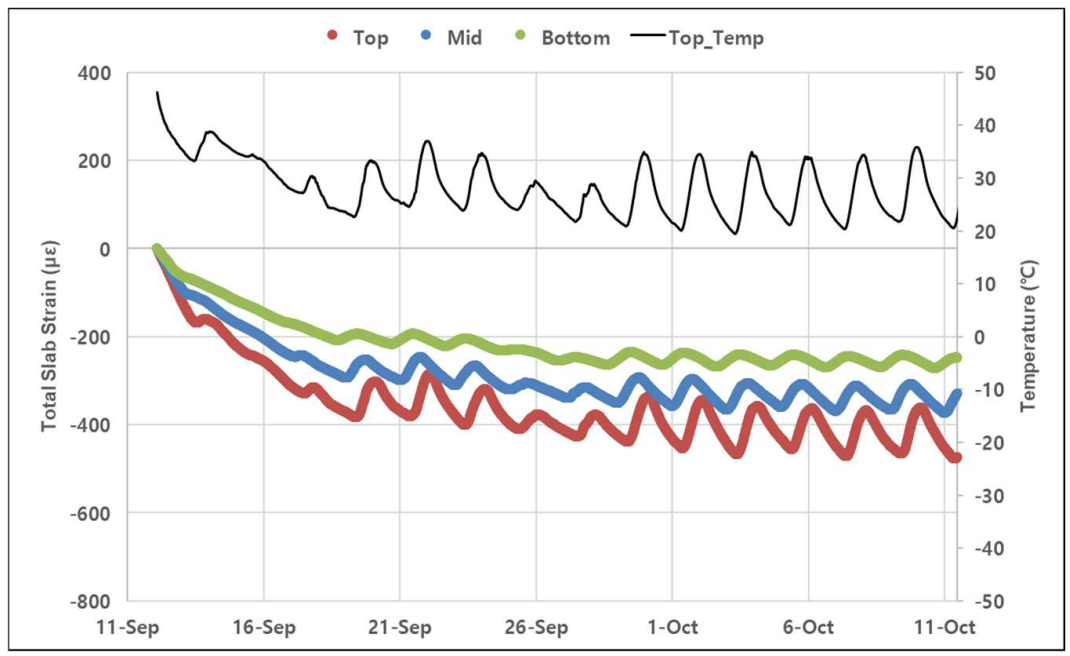

Figure 9. Plots of total strain of field slab at different depths as a function of time.

Using the methodology presented herein, the total strain according to five different environmental conditions can be derived, as shown in Figure 10. In the case of the field specimens, the results showed that the fluctuation pattern was identical between specimens as the top open and the all-blocked specimens were subject to the same temperature condition; the total shrinkage of the all-blocked specimen wherein drying shrinkage was prevented, was smaller. Regarding the differences between the chamber specimens, clear differences in the shrinkage can be confirmed as the temperature and humidity conditions were controlled at constant values. In the case of total strain on the slab surface, a smaller fluctuation pattern than that of the beam specimen was confirmed. This indicates that given that only the top of the slab was exposed to the external environment compared with the entire area in the case of a beam specimen, the effect of thermal strain was reflected in the result. 


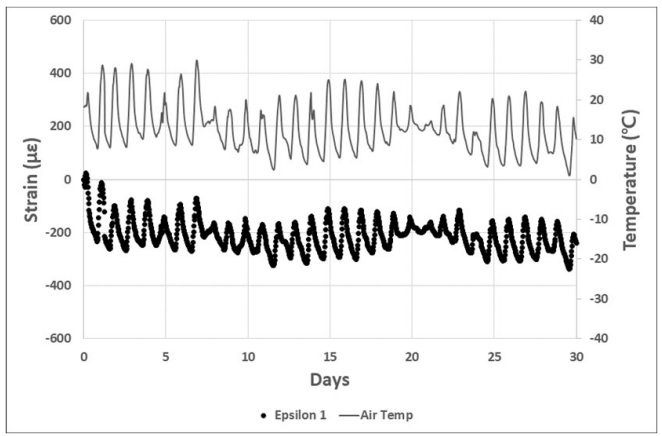

(a) $\varepsilon_{-} \llbracket 1 \rrbracket:$ Field Top-Open Specimen

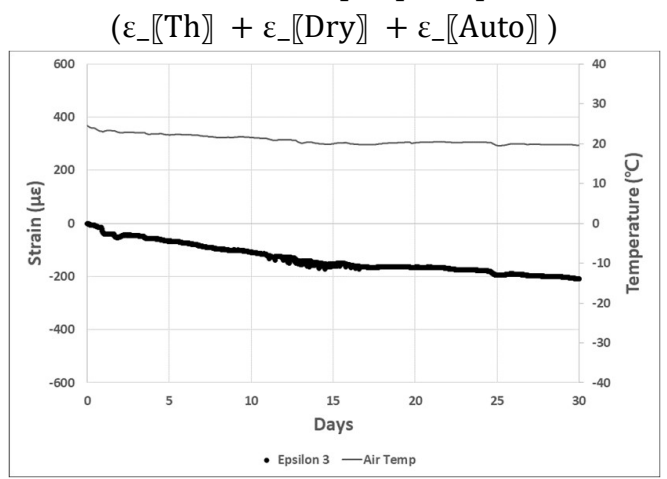

(c) $\varepsilon_{-}$『3』: Chamber Top-Open Specimen

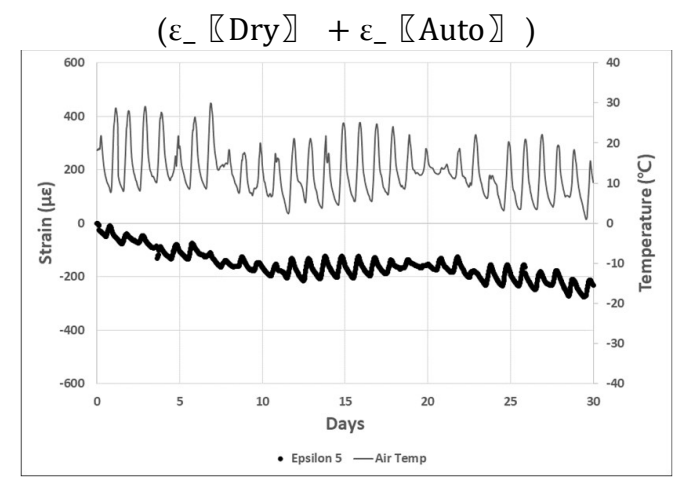

(e) $\varepsilon_{-}$『5】: Field Slab

$\left(\varepsilon_{-}\right.$『Th $+\varepsilon_{-}$『Dry】 $+\varepsilon_{-}$『Auto】 $)$



(b) $\varepsilon_{-} \llbracket 2 \rrbracket:$ Field All-blocked Specimen

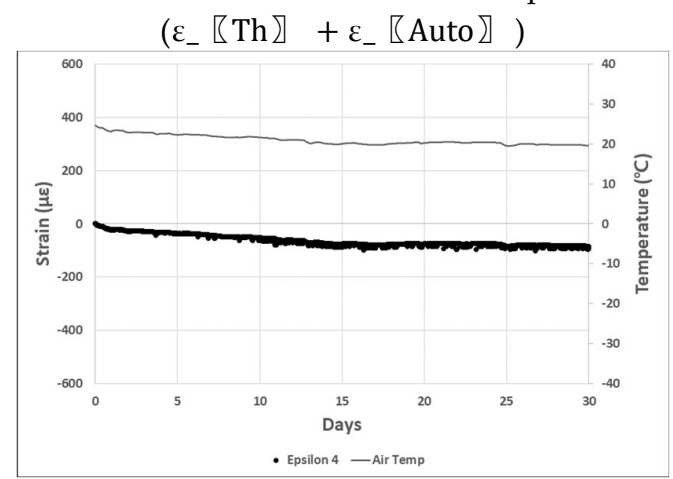

(d) $\varepsilon_{-} \llbracket 4 \rrbracket:$ Chamber All-blocked Speci-

men

$\left(\varepsilon_{-}\right.$『Auto $\left.\rrbracket\right)$

Figure 10. Results of independent shrinkage strain.

\subsection{Comparison Analysis of Drying Shrinkage Derivation Methods}

In the conventional NC method, the drying shrinkage strain was derived by subtracting the INC strain (which is subject only to changes in temperature) from the PNC strain with arbitrary changes in the temperature and humidity. However, with this conventional method, it is difficult to measure the drying shrinkage on the surface of a real slab because the strain can be measured only at a depth of at least $5 \mathrm{~cm}$ from the surface. As shown in Figure 11, the evaluation results of the drying shrinkage strain obtained by the proposed and by the NC methods using the same material were compared.

In the case of the NC method, drying shrinkage strain values up to $-52 \mu \varepsilon$ were calculated, whereas the drying shrinkage strain obtained by the newly proposed method where the sensor was embedded at a depth of $3 \mathrm{~cm}$ from the surface was calculated at a 
maximum of $-80 \mu \varepsilon$, thus yielding a higher strain by $54 \%$ compared with the results of the conventional method.

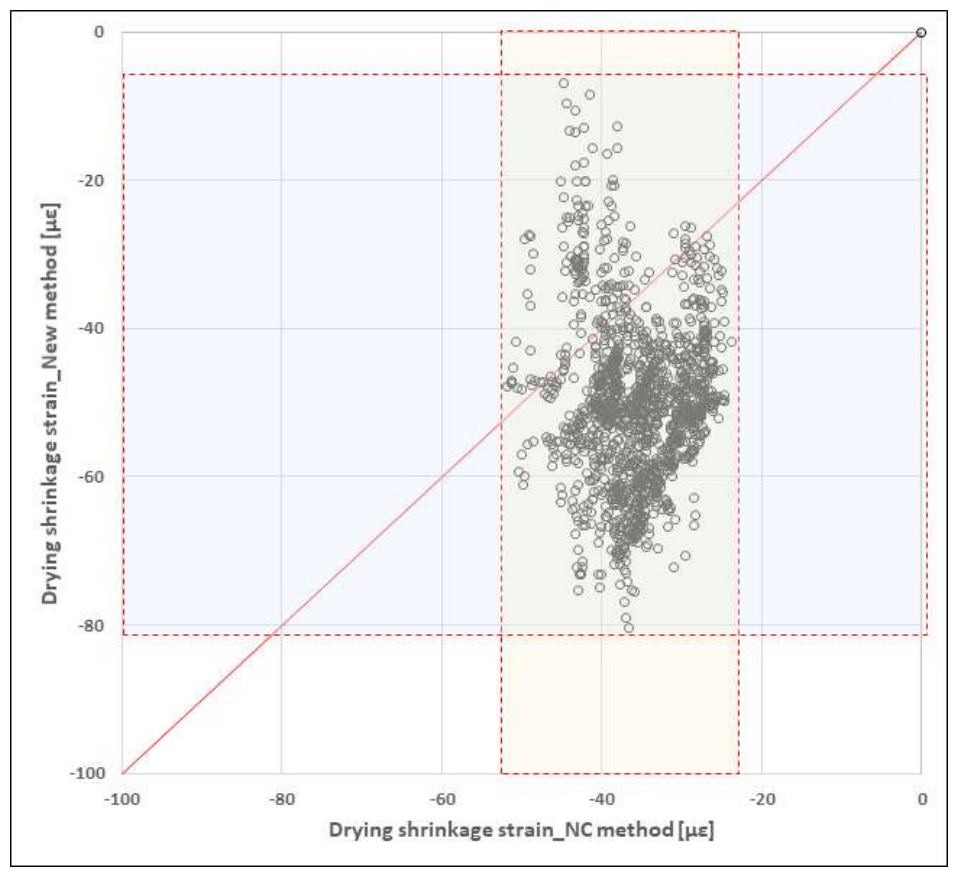

Figure 11. Comparison analysis of dry shrinkage strain calculated by the newly proposed and NC methods.

\subsection{Comparison of Analysis of Stress-dependent Strain Derivation Methods}

The nonstressed state is the state of no resistance to the shrinkage and expansion of the concrete mixture by the environmental load; this state can be reproduced by fabricating environment-controlled beam specimens. However, the bottom of a real slab is constrained by the self-weight, which acts as a stress resisting shrinkage/expansion.

To derive the stress-dependent strain, it is important to measure the nonstressed strain caused by the early-age hydration and environmental factors. Based on basic concepts, it is reasonable to calculate the stress-dependent strain as the difference between the total strain of a slab with restraints at the bottom part and the field top open beam specimen. However, given that the degree of exposure to ambient temperature is different, it is important to eliminate only the thermal strain from the total strain in each case. In the case of the slab, the coefficient of thermal expansion (COTE) was derived from the slope of the temperature and strain graph, and the value multiplied by the temperature difference $(\Delta T)$ was subtracted from the total strain. In the case of a beam specimen, the thermal strain was calculated by subtracting the total strain of the chamber all-blocked specimen from the field all-blocked specimen, and this was subtracted from the total strain of the field top open specimen to derive the stress-dependent strain.

Figure 12 shows the strain-dependent plots after the thermal strain was subtracted. The fluctuation due to the daily temperature difference was eliminated, and given that the other conditions were identical, the difference between the two values can be interpreted as a strain for the stress caused by the restraint of the slab. As a result, as shown in Figure 13, it can be observed that a tensile strain of approximately $100 \mu \varepsilon$ occurred. Thus, with the newly proposed method, it was possible to derive the stress-dependent strain value in a more intuitive and clearer manner than the conventional NC method. 


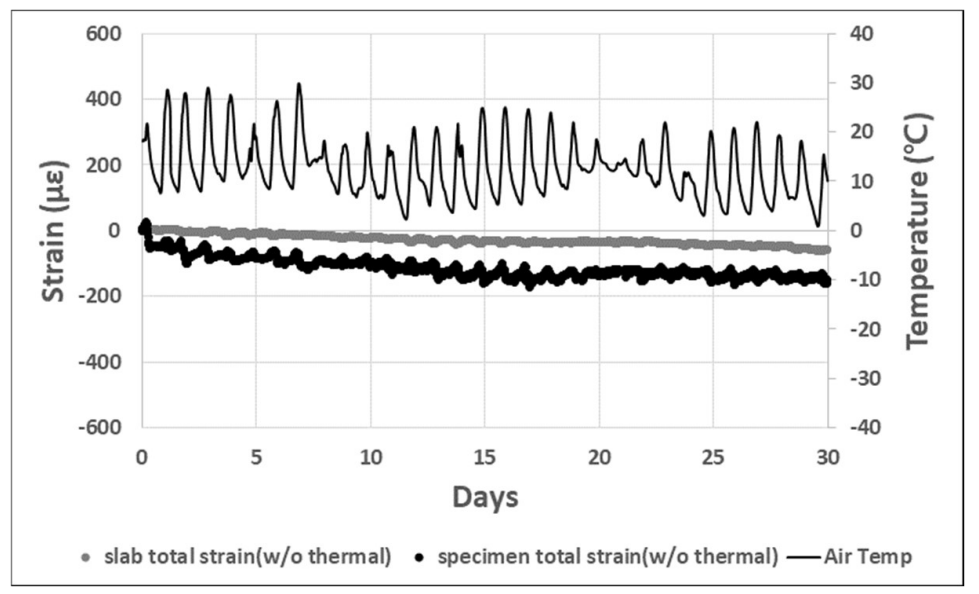

Figure 12. Total strain of slab and specimen (thermal strain was excluded).

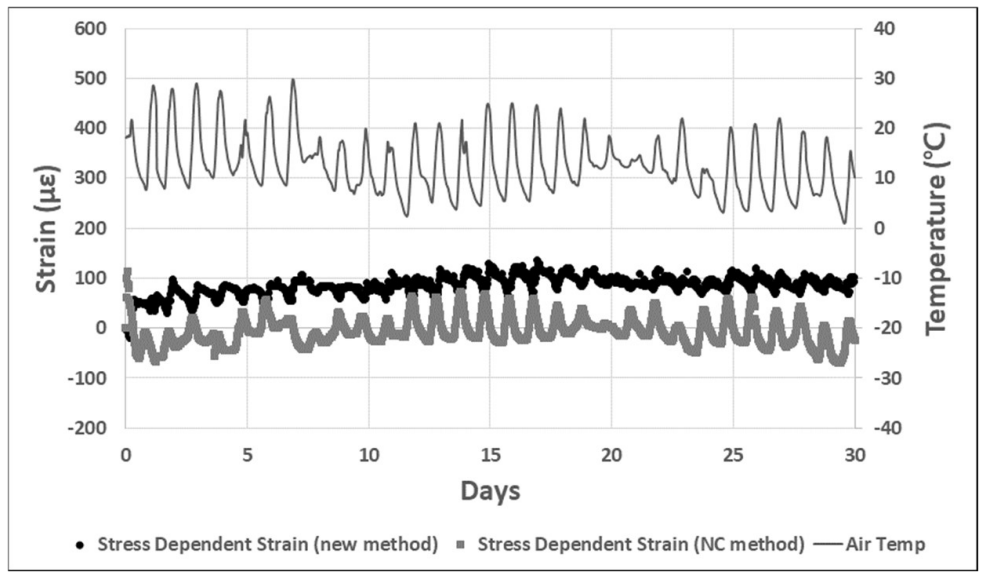

Figure 13. Comparison analysis of stress-dependent strain of newly proposed and nonstressed cylinder methods.

\section{Conclusions}

In this study, an intuitive and reasonable new methodology associated with the evaluation of the shrinkage strain was developed by addressing the limitation of the conventional measurement of drying shrinkage strain, which is critically affected on the slab surface, and by controlling the factors on the early-age shrinkage. The proposed method is convenient, reliable, and can be used to evaluate the shrinkage strain of field concrete pavement. Its superiority was verified by comparatively analyzing its results with that of the conventional measurement methodology of the nonstressed system in field applications.

Strain behavior was evaluated by installing a strain gauge on the surface of the slab specimen and four types of nonstressed specimens, top-open and the all-blocked specimens covered with aluminum tape placed in the field and in an environment-controlled chamber. Using nonstressed beam specimens at controlled temperature and humidity conditions, autogenous shrinkage, drying shrinkage, and thermal strains were derived. After the elimination of the temperature effects from the slab, which was restrained at its bottom part and the nonstressed beam specimen, the tensile stress and strain applied to the actual slab can be calculated by the difference in strain. Thus, this can be applied to the evaluation of the early cracks.

Autogenous shrinkage can be measured by the strain of the all-blocked specimen placed in an environmental chamber. This was based on the concept based on which there was no temperature/humidity change or moisture loss. Thus, only the autogenous 
shrinkage strain can be measured. The results showed that the lower the $\mathrm{w} / \mathrm{c}$ ratio is, the larger will be the measured autogenous shrinkage strain values.

Drying shrinkage strain is a key factor, and was used for the control of construction and curing quality. It can be calculated by subtracting the total strain of all-blocked specimens from the strain of the field top open specimen. Given that the conventional laboratory test or NC concept is limited in that it does not reflect the effect of drying shrinkage in the field, the new method reflects an improvement in this aspect. As a result of comparative analysis with the conventional NC concept method, approximately $54 \%$ higher drying shrinkage strain was measured at the same conditions. Thus, the effect of drying shrinkage on the real-world pavement can be evaluated quantitatively.

Finally, in the case of stress-dependent strain, unlike the nonstressed beam specimen with free shrinkage/expansion, a stress-dependent strain response was obtained as it occurred in the slab which was restrained at its bottom part. Using the basic concept, the stress-dependent strain can be calculated by subtracting the total strain of the top of the slab from that of the field top-open beam specimen. However, in the case of the beam specimen, unlike the slab in which only the surface was exposed to the environment, the temperature effect occurred across the entire surface; the stress-dependent strain was calculated based on the total strain after the thermal strain was subtracted. As a result, a tensile strain of approximately $100 \mu \varepsilon$ was calculated, which enabled the derivation of more intuitive and clearer results compared with the conventional NC method.

\section{Future Research}

The superiority of the improved measurement methodology of early-age shrinkage strain in field concrete (based on the use of nonstressed beam specimens proposed in this study) was verified based on comparisons with the conventional method; however, to establish the allowable criteria for each of the shrinkage and stress-dependent strain types, a sensitivity analysis is required. Furthermore, additional research is needed to propose an optimal mix design suitable for the environmental conditions in the field, such as changes in the autogenous shrinkage strain according to curing method and w/c ratio.

Author Contributions: Conceptualization, H.-H.S.; methodology, R.-S.H.; software, H.-H.S.; validation, K.-J.W.; formal analysis, K.-J.W.; investigation, R.-S.H.; resources, K.-J.W.; data curation, R.S.H.; writing-original draft preparation, H.-H.S.; writing-review and editing, R.-S.H.; visualization, K.-J.W.; supervision, H.-H.S.; project administration, R.-S.H. All authors have read and agreed to the published version of the manuscript.

Funding: This study was carried out as a part of the "Development of high-performance concrete pavement maintenance technology to extend roadway life (21POQW-B146707-04)" research task funded by the Korea Agency for Infrastructure Technology Advanced. The research support is greatly appreciated.

Institutional Review Board Statement: Not applicable.

Informed Consent Statement: Not applicable.

Data Availability Statement: Not applicable.

Acknowledgments: We conducted this study with research support from the Ministry of Land, Infrastructure and Transport, and the Korea Agency for Infrastructure Technology Advancement under the traffic and distribution project "Development of high-performance concrete pavement maintenance technology to extend roadway life (21POQW-B146707-04)". We express our gratitude to everyone involved. 


\section{References}

1. Zhang, M.H.; Tam, C.T.; Leow, M.P. Effect of water-to-cementitious materials ratio and silica fume on the autogenous shrinkage of concrete. Cem Concr Res 2003, 33(10), 1687-1694. doi:10.1016/s0008-8846(03)00149-2.

2. Pane, I.; Hansen, W. Early age creep and stress relaxation of concrete containing blended cements. Mater Struct 2002, $35(2), 92$. doi:10.1007/BF02482107.

3. Holt., E.E. Early age autogenous shrinkage of concrete. Technical Research Center of Finland ESPOO 2001, (2001), VTT Publications 446.

4. Wu, L.; Farzadnia, N.; Shi, C.; Zhang, Z.; Wang, H. Autogenous shrinkage of high performance concrete: A review. Construct Build Mater 2017, 149, 62-75. doi:https://doi.org/10.1016/j.conbuildmat.2017.05.064.

5. Lee, Y.; Yi, S.-T.; Kim, M.-S.; Kim, J.-K. Evaluation of a basic creep model with respect to autogenous shrinkage. Cem Concr Res 2006, 36(7), 1268-1278. doi:10.1016/j.cemconres.2006.02.011.

6. Tanesi, J.; Crawford, G.L.; Nicolaescu, M.; Meininger, R.; Gudimettla, J.M. New AASHTO T336-09 coefficient of thermal expansion test method. J Transp Res Board b 2010, 2164(1), 52-57. doi:10.3141/2164-07.

7. Maruyama, I.; Teramoto, A. Impact of time-dependant thermal expansion coefficient on the early-age volume changes in cement pastes. Cem Concr Res 2011, 41(4), 380-391. doi:10.1016/j.cemconres.2011.01.003.

8. Maruyama, I.; Teramoto, A.; Igarashi, G. Strain and thermal expansion coefficients of various cement pastes during hydration at early ages. Mater Struct 2013, 47(1-2), 27-37. doi:10.1617/s11527-013-0042-4.

9. Choi, S.; Won, M.C. Thermal strain and drying shrinkage of concrete structures in the field. ACI Mater J 2010, 107(5), 498-507. Retrieved from https://www.proquest.com/scholarly-journals/thermal-strain-drying-shrinkage-concrete/docview/762997546/se2?accountid $=10113$

10. Wyrzykowski, M.; Lura, P. Controlling the coefficient of thermal expansion of cementitious materials - A new application for superabsorbent polymers. Cem Concr Composites 2013, 35(1), 49-58. doi:10.1016/j.cemconcomp.2012.08.010.

11. Nehdi, M.; Soliman, A.M. Early-age properties of concrete: overview of fundamental concepts and state-of-the-art research. Proc Inst Civ Eng - Constr Mater 2011, 164(2), 57-77. doi:10.1680/coma.900040.

12. Yang, K.-H.; Cheon, J.H.; Kwon, S.-J. Modeling of chloride diffusion in concrete considering wedge-shaped single crack and steady-state condition. Comput Concr 2017, 19(2), 211-216. https://doi.org/10.12989/CAC.2017.19.2.211.

13. Hoover, C.G.; Bažant, Z.P. Universal size-shape effect law based on comprehensive concrete fracture tests. J Eng Mech 2014, 140(3), 473-479. doi:10.1061/(asce)em.1943-7889.0000627.

14. Viviani, M.; Glisic, B.; Smith, I.F.C. Separation of thermal and autogenous deformation at varying temperatures using optical fiber sensors. Cem Concr Composites 2007, 29(6), 435-447. doi:10.1016/j.cemconcomp.2007.01.005.

15. Mihashi, H.; de Barros Leite, J.P. State-of-the-Art report on control of cracking in early age concrete. J Adv Concr Technol 2004, 2(2), 141-154. doi:10.3151/jact.2.141.

16. Zhang, J.; Hou, D.; Han, Y. Micromechanical modeling on autogenous and drying shrinkages of concrete. Constr Build Mater 2012, 29, 230-240. doi:10.1016/j.conbuildmat.2011.09.022

17. Ole M. J.; Per F. H. Autogenous deformation and RH-change in perspective. Cem Concr Res 2001, 31(12), 6.

18. Guan, Y.; Gao, Y.; Sun, R.; Won, M.C.; Ge, Z. Experimental study and field application of calcium sulfoaluminate cement for rapid repair of concrete pavements. Front Struct Civ Eng 2017, 11(3), 338-345. doi:10.1007/s11709-017-0411-0.

19. Rahimi-Aghdam, S.; Rasoolinejad, M.; Bažant, Z.P. Moisture diffusion in unsaturated self-desiccating concrete with humiditydependent permeability and nonlinear sorption isotherm. J Eng Mech 2019, 145(5). doi:10.1061/(asce)em.1943-7889.0001591.

20. Lura, P.; Jensen, O.M., Measuring techniques for autogenous strain of cement paste. Mater Struct 2006, 40(4), 431-440.

21. Yeon, J.H.; Choi, S.; Ha, S.; Won, M.C. Effects of creep and built-in curling on stress development of Portland cement concrete pavement under environmental loadings. J Transport Eng 2013, 139(2), 147-155. doi:10.1061/(asce)te.1943-5436.0000451.

22. Yeon, J.H.; Choi, S.; Won, M.C. In situ measurement of coefficient of thermal expansion in hardening concrete and its effect on thermal stress development. Construct Build Mater 2013, 38, 306-315. doi:10.1016/j.conbuildmat.2012.07.111.

23. Nam, B.H.; Yeon, J.H.; Behring, Z. Effect of daily temperature variations on the continuous deflection profiles of airfield jointed concrete pavements. Construct Build Mater 2014, 73, 261-270. doi:10.1016/j.conbuildmat.2014.09.073.

24. Wyrzykowski, M.; Lura, P. Moisture dependence of thermal expansion in cement-based materials at early ages. Cem Concr Res 2013, 53, 25-35. doi:10.1016/j.cemconres.2013.05.016.

25. Yeon, J.H.; Choi, S.C.; Won, M.C. Evaluation of zero-stress temperature prediction model for Portland cement concrete pavements. Construct Build Mater 2013, 40, 492-500.

26. Yeon, J. H.; Choi, S.; Won, M.C. Evaluation of zero-stress temperature prediction model for Portland cement concrete pavements. Construct Build Mater 2013, 40, 492-500. doi:10.1016/j.conbuildmat.2012.10.013. 